\title{
37. DATA REPORT: MEASUREMENTS OF MAGNETIC SUSCEPTIBILITY FOR THE OLIGOCENE AND LOWER MIOCENE OF SITE $925^{1}$
}

\author{
Graham P. Weedon ${ }^{2}$
}

\section{INTRODUCTION}

During Ocean Drilling Program (ODP) Leg 154, rotary cores were obtained through lower Miocene to upper Eocene strata in Hole 925A. Frequently, the cores, though cylindrical, did not fill the core liners. This affected the values of volume-calibrated measurements such as magnetic susceptibility (MS) and natural gamma-ray counts obtained on unsplit whole rounds. New magnetic susceptibility measurements are reported here for Cores 154-925A-17R through 54R (Table 1). The measurements were made using a Bartington Instruments MS ferrite probe in contact with the split-core surfaces. Values were obtained at $5-\mathrm{cm}$ intervals using the slower, higher sensitivity setting. Before and after each reading, a single background (air) reading was made to allow correction for linear background drift. The drift mainly results from temperature variations in the environment, although these were minimal in the Bremen Core Repository.

\section{RESULTS AND DISCUSSION}

The Bartington ferrite probe senses a rock volume on the order of $2 \mathrm{~cm}^{3}$; that is, a considerably smaller volume than the shipboard loop sensor (about $180 \mathrm{~cm}^{3}$ ). To compare the new readings to shipboard values, 30 measurements were made on Sections 154-926B-52X-2 and $52 \mathrm{X}-3$. This core was chosen because (1) it was obtained from late Oligocene strata from a site adjacent to Site 925 at similar water depths; (2) being an extended core-barrel core, it was not affected or much less affected by the reduced core volumes compared to the rotary cores in Hole 925A; and (3) it was known to exhibit a large range of MS in the Oligocene interval from the shipboard measurements. The shipboard measurements were converted to SI units by multiplying by $7.7 \times 10^{-6}$ (Curry, Shackleton, Richter, et al., 1995). Comparison of the shipboard and new measurements made at $10-\mathrm{cm}$ spacing reveals a good match in the pattern of stratigraphic variations and a high correlation (Fig. 1). When the new measurements made at $5-\mathrm{cm}$ intervals are illustrated, the greater resolution of the new record is apparent (Fig. 1). The 5-cm measurement spacing was used for Hole 925A to provide high-resolution time series for subsequent spectral analysis (Weedon et al., this volume). The precision of the new measurements is $\pm 0.225 \times 10^{-5}(2 \sigma)$ dimensionless ratio in SI for volume magnetic susceptibility. All the new values are illustrated stratigraphically next to the shipboard values in Figure 2.

It is apparent that for the same rock intervals, the new values for Hole $925 \mathrm{~A}$ vary slightly less than the shipboard values (Fig. 1). This

'Shackleton, N.J., Curry, W.B., Richter, C., and Bralower, T.J. (Eds.), 1997. Proc. ODP, Sci. Results, 154: College Station, TX (Ocean Drilling Program).

${ }^{2}$ Department of Geology, University of Luton, Park Square, Luton, Bedfordshire, LU1 3JU, United Kingdom. graham.weedon@luton.ac.uk
Table 1. New magnetic susceptibility measurements.

\begin{tabular}{lcc}
\hline $\begin{array}{c}\text { Core, section, } \\
\text { interval }(\mathrm{cm})\end{array}$ & $\begin{array}{c}\text { Depth } \\
(\mathrm{mbs})\end{array}$ & $\begin{array}{c}\text { MS } \\
\left(\times 10^{-5} \mathrm{SI}\right)\end{array}$ \\
\hline 154-925A- & & \\
17R-1, 0 & 438.90 & 1.57 \\
17R-1, 5 & 438.95 & 1.38 \\
17R-1, 10 & 439.00 & 1.82 \\
17R-1, 15 & 439.05 & 2.39 \\
17R-1, 20 & 439.10 & 2.76 \\
17R-1, 25 & 439.15 & 3.58 \\
17R-1, 30 & 439.20 & 3.64 \\
17R-1, 35 & 439.25 & 3.20 \\
17R-1, 40 & 439.30 & 2.64 \\
\hline
\end{tabular}

Only a part of the table is produced here. The entire table appears on the CD-ROM.

is contrary to expectation as the loop-sensor used on board measures a much larger stratigraphic interval than the ferrite probe. A greater sensitivity by the loop sensor might explain this.

To compare the two sets of measurements in a different manner, shipboard carbonate data were used whenever the carbonate sample interval lies within $1 \mathrm{~cm}$ of the center of the depth intervals at which MS was measured (yielding 36 values). Figure 3A shows a slightly higher degree of correlation with carbonate for the new MS measurements ( $r=-0.935$ vs. -0.949 ). The volume MS for pure calcite quoted by Collinson (1983) is $-0.48 \times 10^{-5} \mathrm{SI}$. Extrapolation of the regression lines to $100 \%$ carbonate (giving +0.04 from the shipboard data and -0.30 for the new data) indicates that the new values provide a more accurate estimate of carbonate contents for the most carbonaterich samples. Despite this difference in accuracy, the estimates of carbonate inferred from MS generally agree fairly well between the shipboard and new values (Fig. 3B). This suggests that the reduced diameter of the rotary cores from Hole 925A probably had only a minor affect on the shipboard MS values.

\section{ACKNOWLEDGMENTS}

This work was supported by NERC Grant No. GST/02/971 from the ODP Special Topic funds.

\section{REFERENCES}

Collinson, D.W., 1983. Methods in Rock Magnetism and Palaeomagnetism: New York (Chapman Hall).

Curry, W.B., Shackleton, N.J., Richter, C., et al., 1995. Proc. ODP, Init. Repts., 154: College Station, TX (Ocean Drilling Program).

Date of initial receipt: 11 December 1995

Date of acceptance: 10 April 1996

Ms 154SR-137 


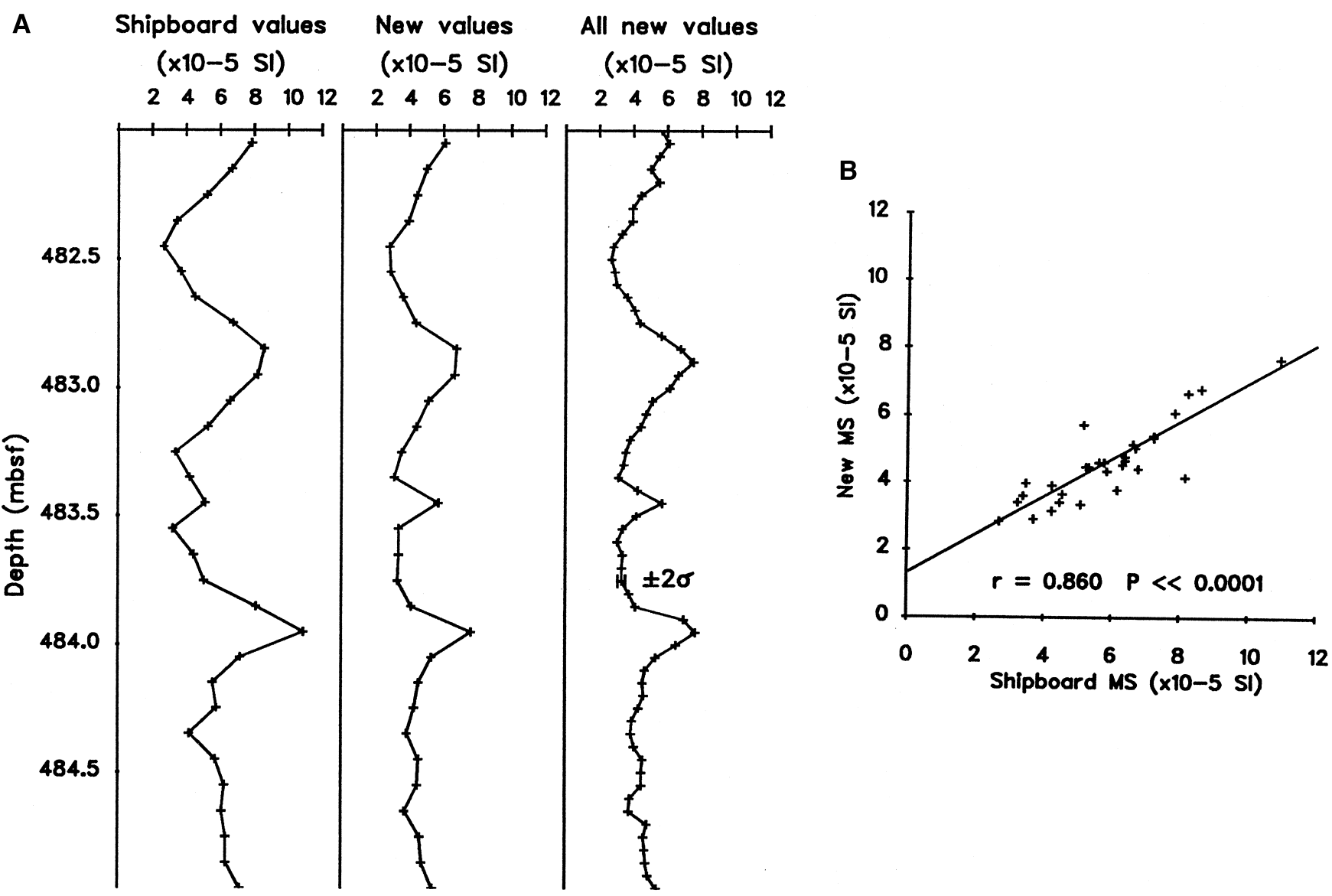

Figure 1. A. Comparison of shipboard measurements using the Bartington loop (left) and new magnetic susceptibility measurements using the Bartington ferrite probe. The measurements were made on Sections 154-926B-52X-2 and 52X-3 as this core material more completely filled the core liners than the rotary cores from Hole 925A. At 10-cm spacing, the new values faithfully reproduce the signal recorded on board (middle). At 5-cm spacing, the new measurements provide much greater stratigraphic resolution (right). B. The shipboard and new MS values are highly correlated. The regression line has the equation $\mathrm{MS}_{\text {new }}=0.565 \times$ $\mathrm{MS}_{\text {shipboard }}+1.311$. 


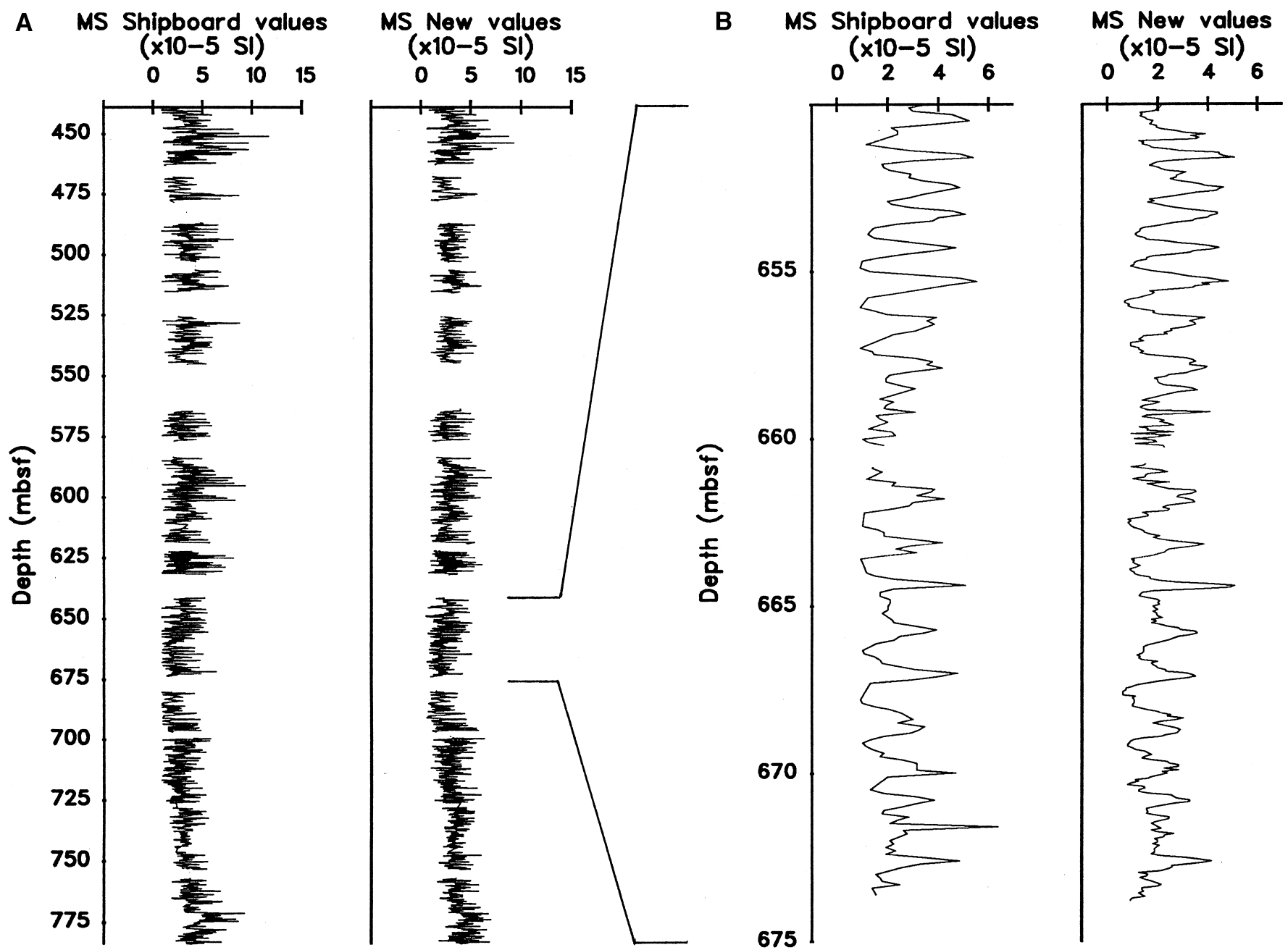

Figure 2. A. Shipboard values (left) and new values (right) for the entire remeasured interval for cores from Hole 925A. B. Shipboard values (left) and new values (right) in detail for the interval from 650 to $675 \mathrm{mbsf}$. 
A
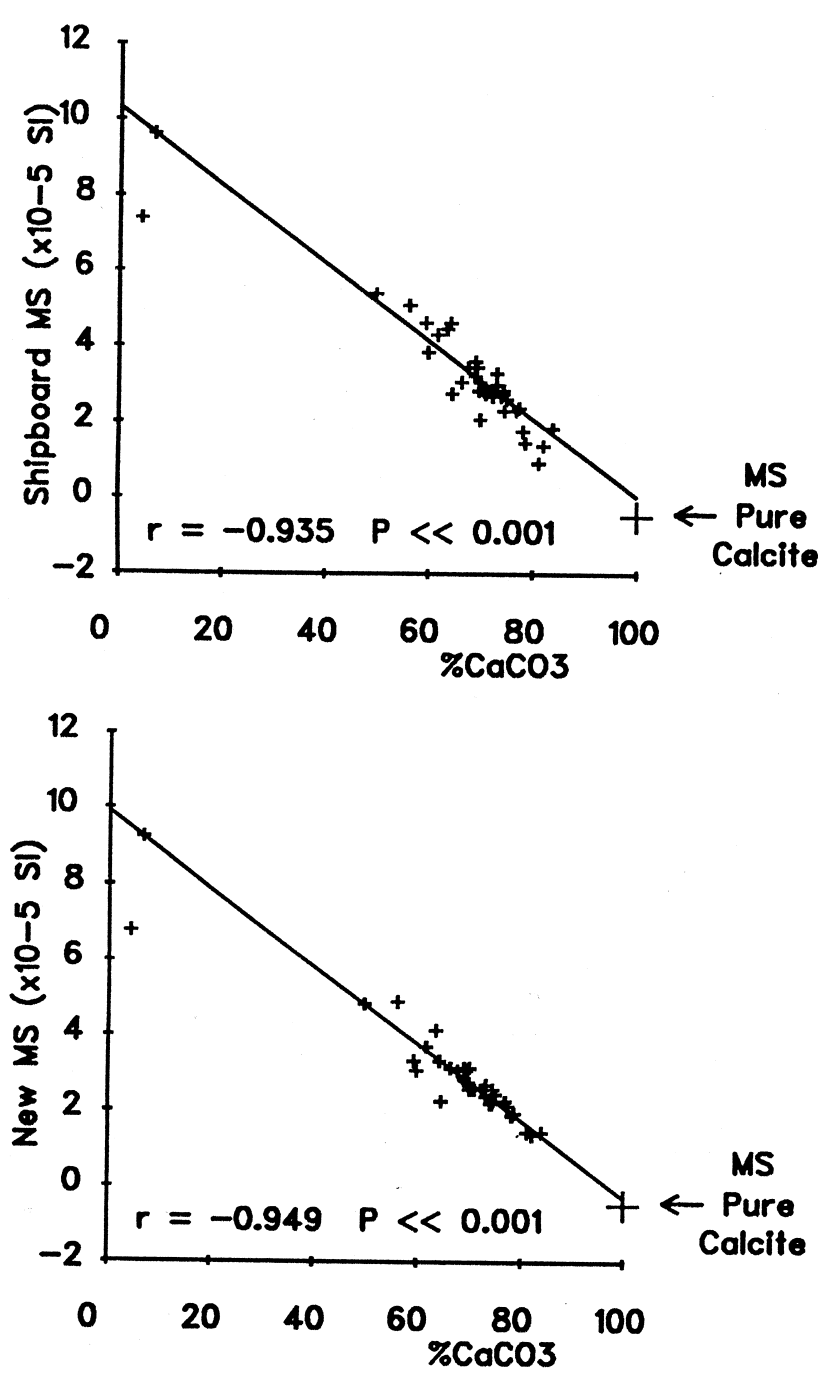

B

$\% \mathrm{CaCO} 3$

from Shipboard MS

$8060 \quad 40200$

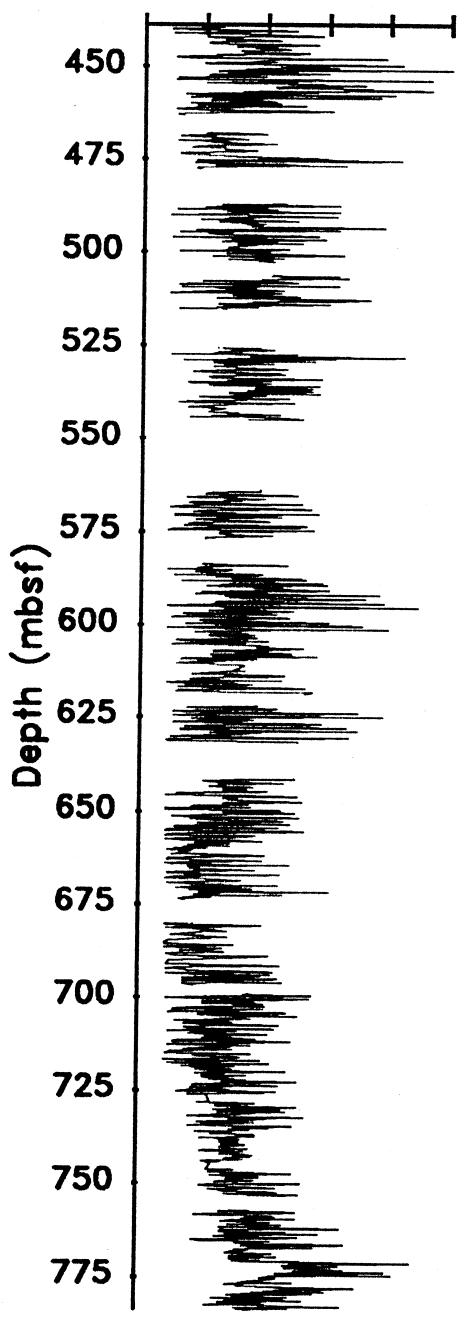

\% $\mathrm{CaCO} 3$ from New MS 806040200

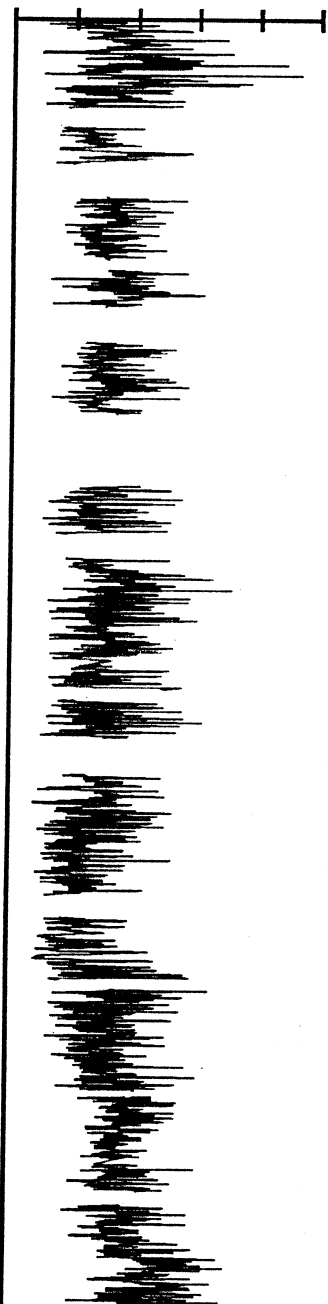

Figure 3. A. Using shipboard carbonate data at intervals from throughout the remeasured cores, there is a good correlation between percent $\mathrm{CaCO}_{3}$ and both the shipboard (top) and new measurements (bottom). The regression equations are $\mathrm{MS}_{\text {shipbard }}=10.307-0.103 \times \% \mathrm{CaCO}_{3}$, and $\mathrm{MS}_{\text {new }}=9.901-0.102 \times \% \mathrm{CaCO}$. B. Estimates of $\% \mathrm{CaCO}_{3}$ inferred from the shipboard and new measurements agree well. 